\title{
PRIMJENA POROZNOG BETONA U KOLNIČKIM KONSTRUKCIJAMA
}

\author{
Melani Felja \\ Sveučilište Josipa Jurja Strossmayera u Osijeku, Građevinski fakultet Osijek, student \\ Krunoslav Ćosić \\ Sveučilište Josipa Jurja Strossmayera u Osijeku, Građevinski fakultet Osijek, mag.ing.aedif. \\ Ivanka Netinger \\ Sveučilište Josipa Jurja Strossmayera u Osijeku, Građevinski fakultet Osijek, docent
}

\begin{abstract}
Sažetak: U radu je dan pregled svojstava poroznog betona te prikazane prednosti njegove uporabe u kolničkim konstrukcijama. Pripremljene su dvije mješavine poroznog betona i mješavina referentnog betona, uobičajeno korištena za izradu betonskih kolničkih konstrukcija, te uspoređena njhova svojstva: konzistencija, tlačna i vlačna čvrstoća, poroznost i gustoća, dinamički modul elastičnosti te propusnost. Procijenjena je i mogućnost njihove primjene u betonskim kolničkim konstrukcijama, sukladno uvjetima propisanim u Općim tehničkim uvjetima za radove na cestama. Mješavina s malim udjelom cementa i dodatkom superplastifikatora nije udovoljila najmanje zahtijevanoj poroznosti i propusnosti za porozne betone. Nasuprot tome, mješavina s većim udjelom cementa i bez dodatka superplastifikatora ocijenjena je kao porozna, no ne posjeduje tlačnu čvrstoću potrebnu za kolničke konstrukcije. Stoga, potrebno je daljnja istraživanja usmjeriti ka poboljšanju tlačne čvrstoće mješavina.
\end{abstract}

Ključne riječi: porozni beton, betonski kolnici, tlačna/vlačna čvrstoća, poroznost, gustoća, dinamički modul elastičnosti, propusnost

\section{APPLICATION OF PERVIOUS CONCRETE IN ROAD CONSTRUCTION}

\begin{abstract}
This paper presents an overview of the properties of porous concrete, and the advantages of its use in pavement structures. Two mixtures of pervious concrete and a reference concrete mixture commonly used for concrete pavements are prepared and their properties compared: consistency, compressive and flexural strength, porosity and density, dynamic modulus of elasticity, as well as permeability. The possibility of their application in concrete pavements is estimated in accordance with the requirements given in General technical conditions for roadworks. Mixture with a small amount of cement and addition of superplasticizer did not meet minimum porosity and permeability required for pervious concrete. In contrast, a mixture with a higher amount of cement and without the addition of superplasticizer was evaluated as pervious one, but does not have a compressive strength required for road construction. Therefore, it is necessary to direct further research towards improving the compressive strength of mixtures of pervious concrete.
\end{abstract}

Key words: pervious concrete, concrete pavements, compression/flexural strength, porosity, density, dynamic modulus of elasticity, permeability 


\section{Uvod}

Razvoj betonskih kolnika započeo je još u doba starih Rimljana [1]. Kolničke konstrukcije toga razdoblja činio je sloj usitnjenog kamenog materijala vezanog prirodnim hidrauličnim vezivom (vulkanski pepeo iz mjesta Pozzuoli kod Napulja) [2]. Izgradnjom prvog cementnog makadama 1888. godine, u Wroclawu započinje moderno doba izgradnje betonskih kolnika [3]. Ipak, prvi klasični betonski kolnik izgrađen je nešto kasnije, 1891. godine u Bellefontaineu, SAD, primjenom samo skromnih zanatskih tehnologija [4]. Prvi strojno izvedeni kolnici pojavljuju se pak u Njemačkoj 1930. godine [5]. U Hrvatskoj se početak izgradnje betonskih kolnika bilježi prije Prvog svjetskog rata i neposredno nakon Drugog svjetkog rata, nakon čega se s izgradnjom betonskih kolnika na hrvatskim cestama potpuno prestalo [1]. Danas se betonski kolnici kod nas izvode samo na posebnim mjestima, poput naplatnih postaja na autocestama ili benzinskih crpki. lako kod nas nisu zastupljeni u velikoj mjeri, betonski kolnici nalaze svoju široku primjenu u razvijenim zemljama, uglavnom u SAD-u te zemljama Europe (Austrija, Njemačka, Belgija, Češka i dr.) [1]. Tako je npr. u Češkoj Republici oko $50 \%$ autocesta izgrađeno od betona [3]. Prednosti betonskih u odnosu na asfaltne kolnike su višestruke. Krutost i čvrstoća betona utječu na distribuciju opterećenja preko relativno široke površine, tako da je opterećenje na posteljicu malo pa su i slojevi ispod betonske ploče manjih dimenzija u usporedbi sa slojevima asfaltnih kolničkih konstrukcija. Povoljna fizičkomehanička svojstva uzrokuju i manje potrebe za održavanjem, popravcima i rekonstrukcijom betonskih kolnika u odnosu na asfaltne kolnike. Naime, kod betonskih kolnika nema deformacija u obliku kolotraga nastalih kretanjem vozila budući da kruta kolnička konstrukcija smanjuje deformiranje kolnika, što u konačnici utječe i na smanjenje potrošnje goriva kod vozila [6]. Manje deformacije kod takvog kolnika znače i smanjenu mogućnost zadržavanja vode na kolniku koja bi mogla utjecati na upravljački sustav vozila, što znatno pridonosi sigurnosti i udobnosti prometa, a naposljetku i povoljno utječe na trajnost kolnika. Smanjena potreba za održavanjem i rekonstrukcijama također utječe na povećanje brzine putovanja i protoka prometa, budući da su smanjeni radovi na kolniku. Dodatno, beton je vrlo svijetao materijal koji dobro reflektira svjetlost nadolazećih vozila i rasvjetnih svjetala, čime se povećava vidljivost i sigurnost noćne vožnje, ublažava stvaranje urbanih toplinskih otoka i smoga [6]. Izgradnjom betonskih kolnika troši se manje goriva tijekom proizvodnje, transporta i zbijanja materijala u konstrukciju [6]. Nadalje, u betonu se mogu upotrijebiti industrijski nusprodukti (leteći pepeo, zgura) čime se smanjuju deponije tih materijala, kao i potrebe za materijalima iz prirodnih izvora. Također, suvremeni betonski kolnici imaju poboljšane površinske teksture, čime predstavljaju dobro rješenje za smanjenje buke te znatno veću otpornost kolničke površine na proklizavanje. Navedeno je naročito izraženo kod kolničkih konstrukcija, čiji je gornji ustroj izveden iz tzv. poroznog betona [6].

Svoj naziv porozni beton duguje velikom udjelu pora koji je posljedica potpunog izostanka ili tek male prisutnosti sitnih čestica agregata u njegovom sastavu, odnosno zbog male volumne koncentracije agregata $u$ betonu ostaje puno šupljina. Prema Putmanu i Neptuneu [7], poroznost ovakvog betona kreće se između 11 i $35 \%$, što su potvrdili i ostali istraživači $[8,9,10]$. Veliki udio pora odgovoran je za najveći nedostatak poroznog betona, njegovu smanjenu čvrstoću. Tlačne čvrstoće takvog betona kreću se u rasponu od $20-30 \mathrm{MPa}$ [11]. No, veliki udio pora osigurava takvom betonu i neke prednosti u odnosu na klasični beton. Naime, zbog visokopropusnih, međusobno povezanih pora, povećano je propuštanje vode kod kolnika izgrađenih poroznim betonom, čime se smanjuje potreba za izgradnjom sustava za odvodnju, umanjuje buka i zagrijavanje [7], olakšava se pročišćavanje vode te se obnavlja dinamička zaliha vode u gradovima. Stoga je porozan beton posebno pogodan za izgradnju parkirališta, nogostupa i biciklističkih staza, kao i za izgradnju propusnih baza i rubnih slivnika te bankina za smanjenje crpljenja ispod betonskog kolnika [12]. Velika poroznost ovog betona doprinosi dobroj apsorpciji zvuka [6]. U usporedbi s običnim betonom, porozni beton ima manji modul elastičnosti i manje izraženo skupljanje [13].

S obzirom na njegov osnovni nedostatak, smanjenu čvrstoću, ispitivanja na poroznom betonu su većinom usmjerena na pronalaženje optimalnog sastava poroznog betona kako bi zadovoljio kriterije tlačne čvrstoće. Prema Yangu i Jiangu [11], tlačnu je čvrstoću moguće poboljšati uporabom sitnih čestica agregata, silikatne prašine te, kao kod običnog betona, dodatkom superplastifikatora. Istodobno, navedene komponente pozitivno utječu na otpornost na trošenje i cikluse smrzavanja i odmrzavanja takvog betona. Prema [14], sitne čestice agregata (pijesak) nepovoljno će utjecati na vlačnu čvrstoću betona, dok će krupne čestice agregata povoljno utjecati na njegovu sposobnost apsorpcije zvuka [15]. Prema [14] i [16], preporučeni udio pijeska u poroznom 
betonu kreće se u granicama 7-10\% ukupne mase agregata, količina cementa za kubni metar betona 270-415 $\mathrm{kg} / \mathrm{m}^{3}$ [17], a vodocementni faktor 0,2-0,45 [17].

$\mathrm{U}$ ovome radu procijenit će se mogućnost uporabe poroznog betona u kolničkim konstrukcijama, pri čemu su osnovni zahtjevi koji se postavljaju za beton kolničkih konstrukcija s obzirom na predviđeno prometno opterećenje, prikazani tablicom 1.

Tablica 1 - Najmanja 28-dnevna karakteristična čvrstoća betona, sukladno OTU za radove na cestama

\begin{tabular}{|l|c|c|}
\hline \multicolumn{1}{|c|}{$\begin{array}{c}\text { Predviđeno prometno } \\
\text { opterećenje }\end{array}$} & $\begin{array}{c}\text { Zahtijevani razred tlačne } \\
\left.\text { čvrstoće (N/mm }{ }^{2}\right)\end{array}$ & $\begin{array}{c}\text { Zahtijevana vlačna čvrstoća savijanjem } \\
\left(\mathbf{N} / \mathbf{m m}^{2}\right)\end{array}$ \\
\hline Vrlo teško & $35 / 45$ & 5,0 \\
\hline Teško & $30 / 37$ & 4,5 \\
\hline Ostalo & $25 / 30$ & 4,0 \\
\hline
\end{tabular}

Pri projektiranju sastava betonskih mješavina poroznog betona vodit će se računa o cijeni takvog betona te pokušati dobiti beton zadovoljavajuće kvalitete, bez uporabe dodataka koji dodatno poskupljuju proizvodnju betona.

\section{Eksperimentalno istraživanje}

\subsection{Projekt sastava betonskih mješavina}

Pri izradi betonskih mješavina korišten je dolomit frakcioniran u frakcije $0-4 \mathrm{~mm}, 4-8 \mathrm{~mm}$ te $8-16 \mathrm{~mm}$ granulometrijskih razreda $G_{F} 85$ (frakcija 0-4 mm), $G_{C} 85 / 20$ (frakcija 4-8 mm) i $G_{C} 90 / 15$ (frakcija 8-16 mm), te pijesak granulometrijskog razreda $\mathrm{G}_{\mathrm{F}} 85$ (frakcija $0-2 \mathrm{~mm}$ ) podrijetlom iz rijeke Drave. Gustoća dolomita iznosila je $2,75 \mathrm{~kg} / \mathrm{dm}^{3}$, a pijeska $2,65 \mathrm{~kg} / \mathrm{dm}^{3}$. U svim mješavinama korišten je cement CEM II/A-M (S-V) 42,5N, gustoće $3,0 \mathrm{~kg} / \mathrm{dm}^{3}$. Superplastifikator koji je korišten u mješavinama je na bazi karboksilnih eter polimera s dugim bočnim lancima. Referentna mješavina betona (M1) je uobičajena mješavina koja se koristi za izradu betonskih kolnika, a sadržava sve tri frakcije agregata (omjer 0-4/4-8/8-16 je bio 40:30:30), $350 \mathrm{~kg}$ cementa u kubnom metru betona te $1 \%$ superplastifikatora zbog poboljšanja obradivosti. Mješavina poroznog betona M2 projektirana je $s$ izrazito malom količinom cementa $(280 \mathrm{~kg})$, dodatkom $1 \%$ superplastifikatora radi poboljšane obradivosti te dominantno krupnim agregatom (omjer 4-8/8-16 je bio 45:45) uz dodatak 10\% pijeska. Kod mješavine poroznog betona M3 povećana je količina cementa na $300 \mathrm{~kg}$, no superplastifikator nije korišten. Agregat u mješavini M3 je bio dominantno krupni (omjer 4-8/8-16 je bio 60:30) uz dodatak 10\% pijeska. Sve tri mješavine projektirane su s istim vodocementnim omjerom, v/c $=0,33$. Sastav betonskih mješavina prikazan je tablicom 2 .

\section{Tablica 2 - Sastav betonskih mješavina}

\begin{tabular}{|l|c|c|c|}
\hline Mješavina & M1 & M2 & M3 \\
\hline \hline Cement $(\mathrm{kg})$ & 350 & 280 & 300 \\
\hline Voda $(\mathrm{kg})$ & 115,5 & 92,4 & 99 \\
\hline v/c & 0,33 & 0,33 & 0,33 \\
\hline Superplastifikator $(\mathrm{kg})$ & 3,5 & 2,8 & - \\
\hline Agregat ukupno $(\mathrm{kg})$ & 2034 & 1813,1 & 1783,7 \\
\hline Pijesak 0-2 mm $(\mathrm{kg})$ & - & 181,3 & 178,4 \\
\hline Agregat 0-4 $\mathrm{mm}(\mathrm{kg})$ & 813,6 & - & - \\
\hline Agregat 4-8 $\mathrm{mm}(\mathrm{kg})$ & 610,2 & 815,9 & 1070,2 \\
\hline Agregat 8-16 mm (kg) & 610,2 & 815,9 & 535,1 \\
\hline
\end{tabular}




\subsection{Izrada uzoraka za ispitivanje svojstava betona}

Na svježem betonu ispitana je konzistencija betona slijeganjem, sukladno normi HRN EN 12350-2:2009 [18]. Dobiveni rezultati prikazani su u tablici 3.

Tablica 3 - Rezultati ispitivanja konzistencije betona slijeganjem

\begin{tabular}{|c|c|}
\hline Mješavina & Konzistencija po metodi slijeganja (cm) \\
\hline \hline M1 & 0,0 \\
\hline M2 & 1,5 \\
\hline M3 & 1,0 \\
\hline
\end{tabular}

Za potrebe ispitivanja tlačne čvrstoće izrađene su 3 kocke brida $15 \mathrm{~cm}$ (slika 1), za ispitivanje vlačne čvrstoće savijanjem i dinamičkog modula elastičnosti izrađene su 3 prizme dimenzija 10/10/40 cm, za ispitivanje gustoće očvrsloga betona 4 kocke brida $15 \mathrm{~cm}$, te za ispitivanje propusnosti valjci promjera $10 \mathrm{~cm}$ i visine $10 \mathrm{~cm}$. Uzorci za ispitivanje propusnosti izrađeni su ugradnjom svježeg betona u nepropusnu plastičnu cijev kojoj je namjera osigurati protjecanje/propusnost vode isključivo u smjeru izvodnice valjka. Unutrašnje stijenke cijevi su prije ispitivanja, odnosno ugradnje, izribane žičanom četkom kako bi se ostvarilo što bolje prianjanje betona i stijenke cijevi.
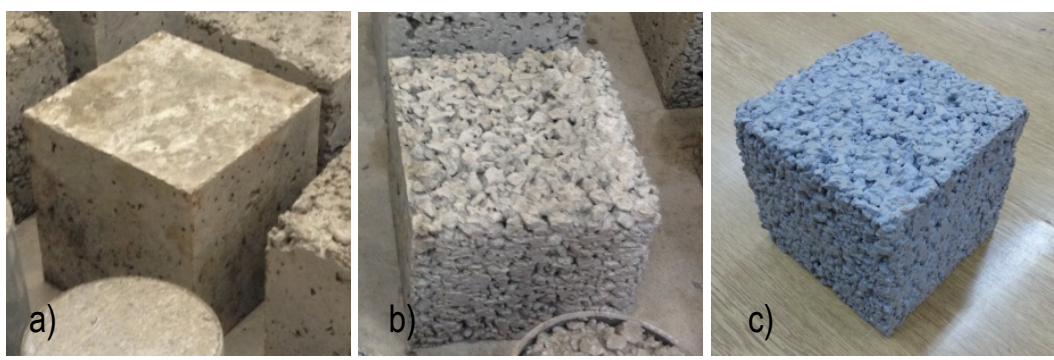

\section{Slika 1 - Uzorci (kocke) očvrsloga poroznoga betona: a) M1; b) M2; c) M3}

Nakon jednog dana starosti, uzorci betona su izvađeni iz kalupa (s izuzetkom uzoraka za mjerenje propusnosti) te potopljeni pod vodu gdje su ostavljeni do 28. dana starosti. Po 28. danu starosti, na uzorcima su ispitana sljedeća svojstva očvrslog betona: tlačna čvrstoća sukladno normi HRN EN 12390-3:2009 [19], vlačna čvrstoća savijanjem sukladno normi HRN EN 12390-5:2002 [20], gustoća očvrsloga betona sukladno normi HRN EN 12390-7:2009 [21], brzina prolaza ultrazvučnog impulsa kroz uzorke (radi određivanja dinamičkog modula elastičnosti) sukladno normi HRN EN 12504-4:2004 [22], propusnost vode i poroznost uzoraka. Propusnost vode određena je mjerenjem brzine prolaza volumena vode od 1 I kroz valjke promjera $10 \mathrm{~cm}$ i visine $10 \mathrm{~cm}$. Poroznost uzoraka određena je računski iz gustoće i obujamske gustoće uzoraka betona. Dinamički modul elastičnosti izračunat je iz brzine prolaza ultrazvučnog impulsa (v), uz pretpostavku Poissonov koeficijenta $(\mu)$ od 0,22 [10], što je u skladu s [23] i uz gustoću očvrslog betona $(\rho)$ prema formuli:

$$
E_{b d}=\frac{v^{\mathrm{ai}} p(1+\mu)(1-2 \mu)}{(1-\mu)}(\mathrm{Pa})
$$

\subsection{Rezultati i rasprava}

Rezultati ispitivanja prikazani su tablicom 4 te slikama 2 do 5 . Sve prikazane vrijednosti srednja su vrijednost svih izmjerenih vrijednosti određenog svojstva. 
Tablica 4 - Rezultati ispitivanja očvrsloga betona

\begin{tabular}{|l|c|c|c|}
\hline Mješavina/Svojstva očvrslog betona & M1 & M2 & M3 \\
\hline \hline Tlačna čvrstoća (MPa) & 69,5 & 38,1 & 24,1 \\
\hline Vlačna čvrstoća savijanjem (MPa) & 9,7 & 7,6 & 4,9 \\
\hline Gustoća očvrslog betona $\left(\mathrm{kg} / \mathrm{m}^{3}\right)$ & 2508 & 2404 & 2349 \\
\hline Poroznost $(\%)$ & 4 & 7 & 12 \\
\hline Brzina prolaza ultrazvučnog impulsa (m/s) & 5357 & 5394 & 4688 \\
\hline Dinamički modul elastičnosti (GPa) & 70,9 & 66,0 & 51,3 \\
\hline
\end{tabular}

Rezultati ispitivanja (tablica 4, slika 2) pokazuju da mješavina poroznog betona M2 ima za 45,2\% manju tlačnu čvrstoću nego referentni beton (mješavina M1). U odnosu na mješavinu poroznog betona $M 3$, mješavina M2 ima veću tlačnu čvrstoću (za 36,7\%), što je za očekivati s obzirom da se povećanjem poroznosti smanjuje čvrstoća betona. Dobivene vrijednosti tlačnih čvrstoća mješavine M3 su u skladu s [24]. Vlačna čvrstoća savijanjem poroznog betona pokazuje sličnu tendenciju kao i tlačna čvrstoća (tablica 4, slika 2), što je u skladu s [25]. Međutim, dobivene vrijednosti vlačne čvrstoće savijanjem poroznog betona su nešto veće nego što to navodi $\mathrm{ACl}$ (American Concrete Institute) u tehničkim informacijama za porozni beton [24]. U odnosu na mješavinu poroznog betona $M 2$, mješavina poroznog betona $M 3$ ima 35,5\% manju vlačnu čvrstoću, dok je vlačna čvrstoća mješavine M2 za 21,6\% manja nego kod referentnog betona, što je nešto manje smanjenje nego kod tlačne čvrstoće. Svojim vlačnim čvrstoćama porozni beton M3 udovoljava uvjetima za ugradnju u kolničke konstrukcije izložene teškom prometnom opterećenju, a porozni beton M2 vrlo teškom prometnom opterećenju. Svojom tlačnom čvrstoćom porozni beton M2 udovoljava uvjetima za ugradnju u kolničke konstrukcije izložene teškom prometnom opterećenju, dok porozni beton M3 uopće ne udovoljava uvjetima.
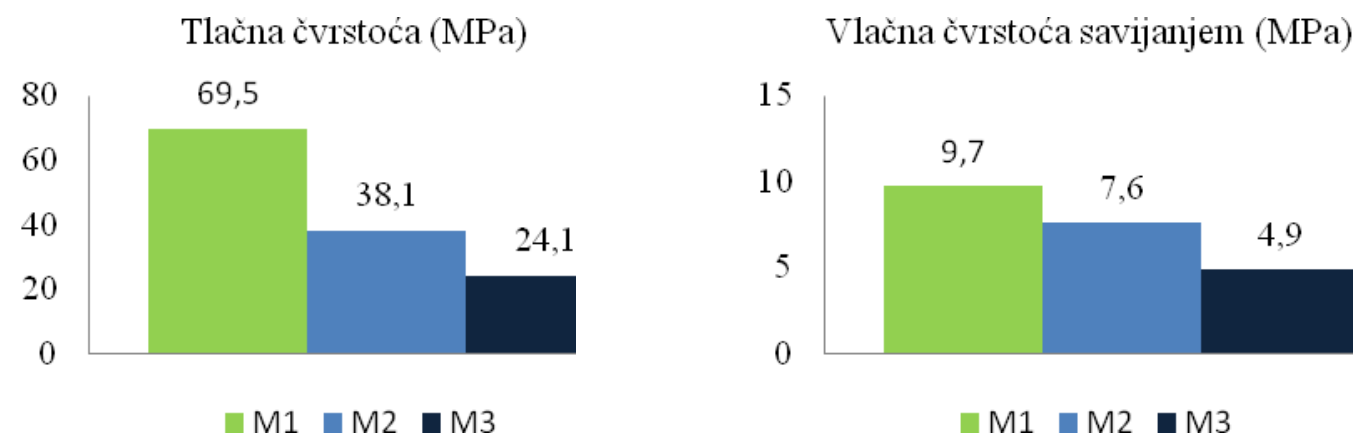

\section{Slika 2 - Rezultati ispitivanja očvrsloga betona: tlačna i vlačna čvrstoća savijanjem}

Poroznost mješavine poroznog betona M2 je iznosila svega 7\% (tablica 4, slika 3), što takav beton sukladno [7] ne svrstava u kategoriju poroznih betona. Ovako mala poroznost posljedica je dodavanja superplastifikatora u mješavinu, koji je u svježem stanju betona uzrokovao klizanje cementne paste sa zrna te procjeđivanje cementne paste na dno kalupa prilikom ugradnje. Poroznost mješavine M3 odgovara granicama koje su u literaturi postavljene za porozni beton.

Dobivene vrijednosti obujamskih gustoća na očvrsnulim uzorcima betona (tablica 4, slika 3) su u skladu s povećanjem poroznosti. Povećanjem udjela pora za $66,7 \%$ (s $4 \%$ kod referentnog betona na $12 \%$ kod mješavine poroznog betona M2) obujamska gustoća betona se smanjila za 6,3\%, što je prikazano na slici 3 . 

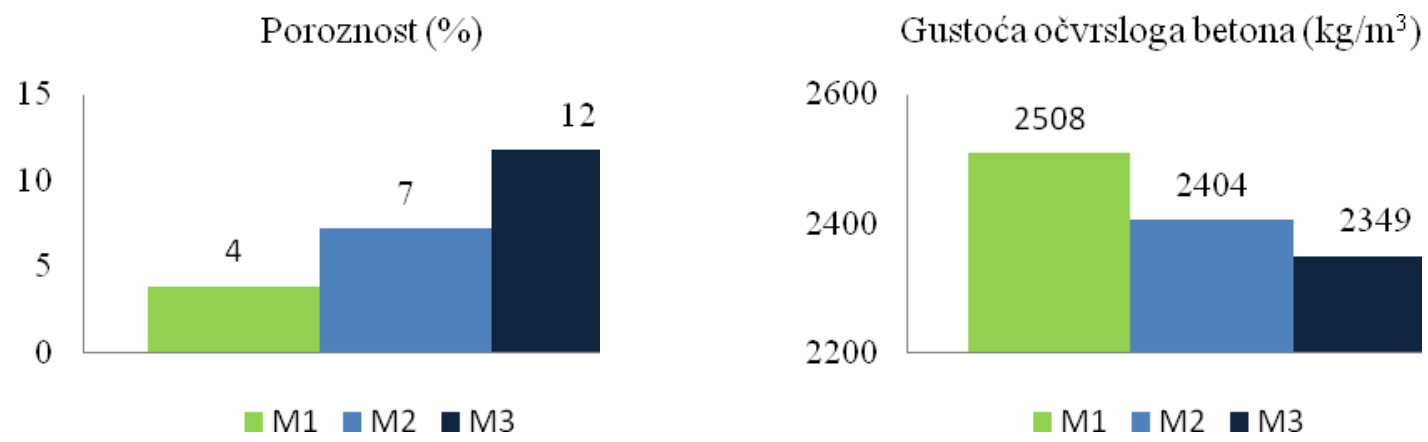

Slika 3 - Rezultati ispitivanja očvrsloga betona: poroznost i gustoća

Dinamički modul elastičnosti (tablica 4, slika 4) mješavine poroznog betona M3 iznosi $51,3 \mathrm{GPa}$, što je za $27,6 \%$ manje nego kod referentnog betona (M1) i za 22,3\% manje nego kod mješavine poroznog betona M2.

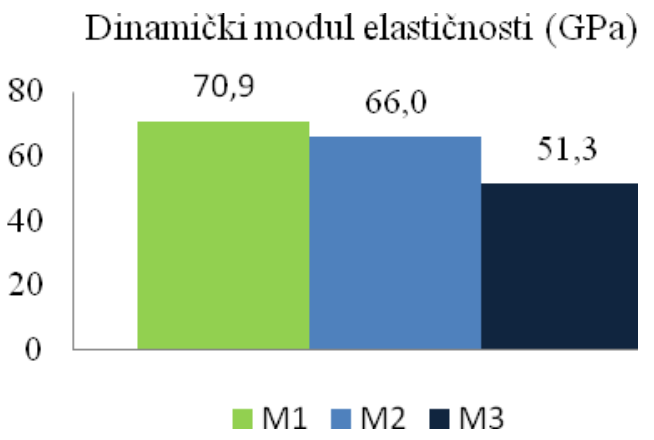

\section{Slika 4 - Rezultati ispitivanja očvrsloga betona: dinamički modul elastičnosti}

Propusnost je ispitana na valjcima njegovanim pod vodom 28 dana, nakon čega je izmjereno vrijeme prolaska 1 litre vode kroz uzorke te izračunata propusnost izražena u L/min $/ \mathrm{m}^{2}$ (tablica 4, slika 5). Uspoređujući mješavinu poroznog betona $\mathrm{M} 3 \mathrm{u}$ odnosu na mješavinu poroznog betona $\mathrm{M} 2$, vidljivo je da postoji jasna veza između poroznosti i propusnosti. Povećanjem poroznosti za 39,0\%, dolazi do povećanja propusnosti za 70,4\%, odnosno propusnost mješavine poroznog betona iznosi $152,5 \mathrm{~L} / \mathrm{min} / \mathrm{m}^{2}$ (slika 5), što je u skladu s donjom granicom propusnosti poroznog betona prema [26].

\section{Tablica 5 - Rezultati ispitivanja propusnosti}

\begin{tabular}{|c|c|c|}
\hline Mješavina & $\begin{array}{c}\text { Vrijeme procjeđivanja } \\
\text { (sek) }\end{array}$ & Propusnost (L/min/m²) \\
\hline M1 & 0,0 & 0,0 \\
\hline M2 & 203,0 & 45,1 \\
\hline M3 & 50,0 & 152,5 \\
\hline
\end{tabular}




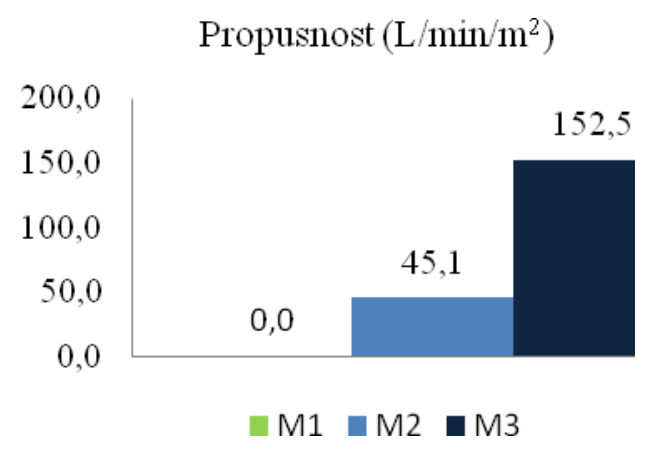

Slika 5 - Rezultati ispitivanja propusnosti

S obzirom na zahtjeve postavljene u literaturi na poroznost i propusnost poroznog betona, mješavina M2 je isključena iz kategorije poroznih betona. Stoga će autori rada svoja daljnja istraživanja usmjeriti na poboljšanje tlačne čvrstoće mješavine $M 3$ te na izradu dodatnih mješavina. Sukladno [14], tlačnu čvrstoću je moguće povećati dodatkom lateksa ili uporabom agregata manjeg maksimalnog nominalnog zrna, budući da se time povećava dodirna površina između zrna agregata. S obzirom na činjenicu da će dodatak lateksa dodatno povisiti cijenu betona, u daljnjim će se istraživanjima pokušati povećati udio zrna 4-8 $\mathrm{mm}$ i/lil udio cementa radi postizanja zahtijevane tlačne čvrstoće poroznog betona [27].

\section{Zaključak}

$\mathrm{U}$ radu je dan pregled svojstava poroznog betona te prikazane prednosti njegove uporabe u kolničkim konstrukcijama. Poštujući pravila projektiranja sastava porozne betonske mješavine navedena u literaturi, spravljene su dvije mješavine poroznog betona i mješavina referentnog betona, uobičajeno korištena za izradu betonskih kolničkih konstrukcija te uspoređena njihova svojstva u očvrslom stanju; tlačna i vlačna čvrstoća, poroznost i gustoća, dinamički modul elastičnosti te propusnost. Također, procijenjena je i mogućnost njihove primjene u betonskim kolničkim konstrukcijama, sukladno uvjetima propisanim u Općim tehničkim uvjetima za radove na cestama. Mješavina s manjim udjelom cementa i dodatkom superplastifikatora nije udovoljila najmanje zahtijevanoj poroznosti i propusnosti za porozne betone. Mješavina s većim udjelom cementa i bez dodatka superplastifikatora ocijenjena je na temelju udjela pora i propusnosti kao porozni beton, no svojom tlačnom čvrstoćom nije udovoljila zahtjevima Općih tehničkih uvjeta za radove na cestama. Stoga će autori rada svoja daljnja istraživanja usmjeriti ka poboljšanju tlačne čvrstoće betona povećanjem udjela frakcije 4-8 $\mathrm{mm}$ i/li udjela cementa. Ispitivanja provedena u radu su preliminarna te će daljnja istraživanja biti usmjerena na veći broj mješavina variracijama u udjelu frakcija $4-8 \mathrm{~mm}$ i 8 - $16 \mathrm{~mm}$. Također, za potpunu ocjenu mogućnosti uporabe poroznog betona u kolničkim konstrukcijama trebalo bi u daljnjim istraživanjima uključiti i ispitivanja otpornosti na trošenje, trajnosti na cikličko smrzavanje i odmrzavanje te apsorpciju buke.

\section{Literatura}

[1] Babić, B.: Projektiranje kolničkih konstrukcija, HDGI, Zagreb, 1997.

[2] Steiger, R. W.: Roads of the Roman Empire, http://www.concreteconstruction.net/images/Roads\%20of\%20the\%20Roman\%20Empire tcm45-342976.pdf

[3] Bjegović, D., Beslać, J., Banjad Pečur, I.: Betonski kolnici u svijetu i u nas, Četvrti hrvatski kongres 0 cestama, Cavtat, 2007.

[4] Snell, L. M., Snell, B. G.: Oldest Concrete Street in the United States, Concrete International, March 2002, pp. $72-74$. 
[5] Stefan Höller, Concrete Pavement Design and Construction in Germany - State of the Art, http://congresodevialidad.org.ar/conferencias-especiales/seminario_icpa/holler.pdf

[6] American Concrete Pavement Association: Green Highways: Environmentally and Economically Sustainable Concrete Pavements - concrete pavement research and technology special report, 2007., http://www.pavements4life.com/QDs/SR385P.pdf

[7] Putman, B. J., Neptune, A. I.: Comparison of test specimen preparation techniques for pervious concrete pavements, Construction and Building Materials, 25 (2011), pp. 3480-3485.

[8] Tennis, P. D., Leming, M. L., Akers, D.J.: Pervious concrete pavements, Technical report, EB302.02. Portland Cement Association, Skokie, Illinois, and National Ready Mixed Concrete Association, Silver Spring, Maryland (2004), pp. 14

[9] Schaefer, V. R., Wang, K., Suleiman, M. T., Kevern, J.: Mix design development for pervious concrete in cold climates, Technical report, National Concrete Pavement Technology Center, lowa State Univ., Ames, lowa (2006), pp. 2

[10] Goede, W. G.: Pervious concrete: Investigation into structural performance and evaluation of the applicability of existing thickness design methods, Washington State University, Department of Civil and Environmental Engineering (2009), pp. 6, 40, dostupno na:

http://www.dissertations.wsu.edu/Thesis/Fall2009/w goede 112409.pdf, pregledano 29.11.2013.

[11] Yang, J., Jiang, G.: Experimental study on properties of pervious concrete pavement materials, Cement and Concrete Research, 33 (2003), pp. 381-386

[12] Blažok, D.: Propusni beton za kolnike, Tehnički glasnik, 4 (2010), str. 15-18, hrcak.srce.hr/file/127819

[13] Ghafoori, N., Dutta, S.: Development of no-fines concrete pavement applications, Journal of Transportation Engineering, 121-3 (1995), pp. 283-288.

[14] Huang, B., Wu, H., Shu, X., Burdette, E. G.: Laboratory evaluation of permeability and strength of polymermodified pervious concrete, Construction and Building Materials, 24 (2010), pp. 818-823

[15] Kim, H. K., Lee, H. K.: Acoustic absorption modeling of porous concrete considering the gradation and shape of aggregates and void ratio, Journal of Sound and Vibration, 329 (2010), pp. 866-879

[16] Kevern, J. T., Schaefer, V. R., Wang, K., Suleiman, M. T.: Pervious concrete mixture proportions for improved freeze-thaw durability, Journal of ASTM International, 5-2 (2008), pp. 1-12

[17] Grace Construction products, Pervious concrete mix proportioning - Technical bulletin TB - 0111, 2006., http://www.na.graceconstruction.com

[18] HRN EN 12350-2:2009 Ispitivanje svježega betona - 2. dio: Ispitivanje slijeganjem

[19] HRN EN 12390-3:2009 Ispitivanje očvrsnuloga betona - 3. dio: Tlačna čvrstoća ispitnih uzoraka

[20] HRN EN 12390-5:2002 Ispitivanje očvrsloga betona - 5. dio: Savojna čvrstoća uzoraka

[21] HRN EN 12390-7:2009 Ispitivanje očvrsnuloga betona - 7. dio: Gustoća očvrsnuloga betona

[22] HRN EN 12504-4:2004 Ispitivanje betona - 4. dio: Određivanje brzine ultrazvučnog impulsa

[23] Wang, H., Li, Q.: Prediction of elastic modulus and Poisson's ratio for unsaturated concrete, International Journal of Solids and Structures, Volume 44, Issue 5 (2007), pp. 1370-1379

[24] American Concrete Institute: Report on Pervious Concrete, Reported by ACI Committee 522 (2010), pp. 7 9

[25] Chen, Y., Wang, K., Wang, X., Zhou, W.: Strength, fracture and fatique of pervious concrete, Construction and Building Materials, Volume 42 (2013), pp. 97-104

[26] Obla, K. H.: Pervious Concrete for Sustainable Development, Recent Advances in Concrete Technology, Washington DC, 2007, http://www.nrmca.org/research/pervious recent advances in concrete technology0707.pdf

[27] Felja, M.: Primjena poroznog betona za izradu kolničkih konstrukcija, završni rad na preddiplomskom sveučilišnom studiju iz kolegija Gradiva, Građevinski fakultet Osijek, Sveučilište Josipa Jurja Strossmayera u Osijeku, 2013 